\title{
A longitudinal study of the impact of COVID-19 restrictions on students' health behavior, mental health and emotional well- being
}

\author{
Peter R Reuter ${ }^{\text {Corresp., } 1}$, Bridget L. Forster ${ }^{1}$, Bethany J. Kruger ${ }^{1}$ \\ ${ }^{1}$ Marieb College of Health \& Human Services, Florida Gulf Coast University, Fort Myers, Florida, United States of America \\ Corresponding Author: Peter R Reuter \\ Email address: preuter@fgcu.edu
}

Background: COVID-related restrictions impacted the lives of students on and off campus during Academic Year 2020/2021. Methods: Our study collected data on student health behavior and habits as well as their mental and emotional health using anonymous surveys. We compared these data with data collected prior to COVID in the longitudinal part of our study ( $n=721$ ) and analyzed them for the cross-sectional part of the study ( $n$ $=506$ ). Results: The longitudinal data show a significant difference for some student behaviors and habits, such as sleeping habits, physical activity, breakfast consumption, time spent online or playing video games, vaping, and marijuana use, during the COVID pandemic compared with pre-COVID data. Respondents also reported a significant increase in difficulty concentrating, remembering, or making decisions, as well as being impacted by feelings of sadness or hopelessness. Yet, there was no increase in the proportion of respondents considering, planning or attempting suicide during COVID. The cross-sectional data illuminate the negative effect of the overall situation and the restrictions on students' mental and emotional well-being. Three-quarters of respondents reported having craved human interaction during the past six months, more than half felt that their mental/emotional health had been impacted by the lack of social events or the switch to virtual (online) teaching. Two-thirds or more of respondents also expressed that they felt less connected to their peers and less motivated in their studies than in previous semesters. Fifty percent or more of respondents selected anxious, stressed, overwhelmed, disconnected, tired, and fatigued as words that best described their emotional state during the pandemic. Conclusions: The impact of COVID-related restrictions on students' behaviors and habits as well as their mental and emotional health was less severe than one would have expected based on studies during the early stage of the pandemic. While some behaviors and habits changed during the COVID pandemic compared with the preCOVID period, the changes were not substantial overall. Our study did not find an increase in the proportion of resnondents considering, planning or attempting suicide during COVID,
Peerj reviewing PDF | (2021:07:63958:2:0:NEW 30 Oct 2021) 
although the cross-sectional data from our survey make the negative effect of the overall situation and the restrictions on students' mental and emotional well-being evident. The impact of the pandemic will unquestionably be long-lasting and will necessitate further and future investigations. 
1 A longitudinal study of the impact of COVID-19 restrictions on students'

2 health behavior, mental health and emotional well-being

3 Peter R. Reuter, Bridget L. Forster, Bethany J. Kruger

5 Marieb College of Health \& Human Services, Florida Gulf Coast University, Florida, United

6 States of America

8 Corresponding Author:

9 Peter Reuter

1010501 FGCU Boulevard South, Marieb Hall 419, Fort Myers, Florida, 33912, USA

11 Email address: preuter@fgcu.edu

\section{ABSTRACT}

Background: COVID-related restrictions impacted the lives of students on and off campus during Academic Year 2020/2021. Methods: Our study collected data on student health behavior and habits as well as their mental and emotional health using anonymous surveys. We compared these data with data collected prior to COVID in the longitudinal part of our study $(\mathrm{n}=721)$ and analyzed them for the cross-sectional part of the study $(n=506)$. Results: The longitudinal data show a significant difference for some student behaviors and habits, such as sleeping habits, physical activity, breakfast consumption, time spent online or playing video games, vaping, and marijuana use, during the COVID pandemic compared with pre-COVID data. Respondents also reported a significant increase in difficulty concentrating, remembering, or making decisions, as well as being impacted by feelings of sadness or hopelessness. Yet, there was no increase in the proportion of respondents considering, planning or attempting suicide during COVID. The crosssectional data illuminate the negative effect of the overall situation and the restrictions on students' mental and emotional well-being. Three-quarters of respondents reported having craved human interaction during the past six months, more than half felt that their mental/emotional health had been impacted by the lack of social events or the switch to virtual (online) teaching. Two-thirds or more of respondents also expressed that they felt less connected to their peers and less motivated in their studies than in previous semesters. Fifty percent or more of respondents selected anxious, stressed, overwhelmed, disconnected, tired, and fatigued as words that best described their emotional state during the pandemic. Conclusions: The impact of 
COVID-related restrictions on students' behaviors and habits as well as their mental and emotional health was less severe than one would have expected based on studies during the early stage of the pandemic. While some behaviors and habits changed during the COVID pandemic compared with the pre-COVID period, the changes were not substantial overall. Our study did not find an increase in the proportion of respondents considering, planning or attempting suicide during COVID, although the cross-sectional data from our survey make the negative effect of the overall situation and the restrictions on students' mental and emotional well-being evident. The impact of the pandemic will unquestionably be long-lasting and will necessitate further and future investigations.

Key words: COVID-19, COVID-related restrictions, student health behavior, students' mental health, students' emotional well-being

\section{INTRODUCTION}

The COVID-19 pandemic started slowly and inconspicuously when the Wuhan Municipal Health Commission in China reported a cluster of pneumonia cases on December 31, 2019 (World Health Organization, 2020). Within one month, the case number had climbed to more than 9,800 worldwide and the death toll exceeded 200, prompting the World Health Organization (WHO) to declare a global health emergency. On March 11, 2020 the WHO declared COVID-19 a pandemic (World Health Organization, 2021). Within a few days, many countries went into some form of lockdown, and most public and private colleges and universities were forced to either shut down temporarily or to transition to online (remote) learning. These sudden and unexpected changes impacted millions of college and university students around the world. Many were forced to move back home or find other alternative living arrangements when campuses and dorms closed. The shift to online teaching also created challenges and struggles for many students as it required a level of hardware, software, and internet connectivity for which many students were not prepared (Aucejo, French, Araya, \& Zafar, 2020; Gillis \& Krull, 2020).

Although the situation differed for students across different countries, studies looking at the impact in the early part of the pandemic (Spring and Summer 2020) equally reported that students experienced high levels of stress that negatively impacted their mental health leading to 
63 increased levels of anxiety and depression (Essadek \& Rabeyron, 2020; Kaparounaki et al., 64 2020; Saddik et al., 2020; Wathelet et al., 2020; Zandifar \& Badrfam, 2020; Zhang et al., 2020;

Baloch et al. 2021; Ochnik et al., 2021). Longitudinal studies that compared data collected from before the pandemic (pre-COVID) with data collected during the pandemic reported similar results. For example, data collected at a university in the United Kingdom in Fall 2019 and Spring 2020 by Evans et al. (2021) showed that students experienced a decrease in well-being and increase in depression. Savage et al. (2020) also collected data from students at a university in the United Kingdom in Fall 2019 and Spring 2020; they too found increased stress levels and a decrease in mental well-being of participating students.

Studies involving college and university students in the US also reported increases in anxiety and depression during this period (Holingue et al., 2020; Jeffery \& Bauer, 2020; Kecojevic et al., 2020; Wang et al., 2020; Hawes et al., 2021). Again, the results of cross-sectional studies were confirmed by longitudinal studies such as the studies by Fruehwirth, Biswas \& Perreira (2021), Giuntella et al. (2021), and Wilson et al. (2021). The study with the largest number of participants in the US was conducted by the Healthy Minds Network (HMN) in association with the American College Health Association (ACHA); more than 18,000 students on 14 campuses participated from late March through May 2020 (Martinez \& Nguyen, 2020). Two-thirds of participants reported experiencing more stress, and one-third had gone through a change in living arrangements. The participants also reported an increase in depression, and $60 \%$ indicated that the pandemic had made it more difficult to access mental health care providers.

There are, however, only a few studies exploring how the sudden changes and restrictions impacted students' health behaviors and habits. Bertrand et al. (2020) collected data from students at two universities in Canada in April/May 2020. They found increased sedentary behavior and alcohol consumption, a reduction in physical activity, and a drop in the quality of the students' diet. A study from the UK comparing pre-COVID (Fall 2019) and COVID (April/May 2020) data reported a decrease in alcohol consumption and a shift in sleep behavior; participants reported staying up later but not sleeping longer (Savage et al., 2020). In the US, Moriarty et al. (2021) found that while some students exercised more and slept longer, other students did just the opposite, while Maher et al. (2021) reported a loss of sleep quality. 
92 Studies from different countries described a decline in physical activity of students during this

93 first part of the pandemic (Savage et al., 2020; Fruehwirth, Biswas \& Perreira, 2021; Giuntella et

94

95

96

97

98

al., 2021; López-Valenciano et al., 2021; Maher et al., 2021). However, two studies from Spain reported opposite results; in the study by Romero-Blanco et al. (2020), physical activity increased during the early lockdown, whereas Castañeda-Babarro et al. (2020) found a decrease in physical activity during the same period. Du et al. (2021) conducted a multinational study involving students in Asia, Europe, and North America that investigated the impact of the pandemic on sleep quality, dietary behavior, and alcohol consumption. They showed a negative impact on the diet of participants and sleep quality; nonetheless, there was no increase in alcohol consumption. Participants in Firkley, Sheinfil \& Woolf-King's (2021) study reported an increase in anxiety and a decrease in quality of life and sleep quality; nonetheless, there was no increase in alcohol or marijuana consumption associated with the change in mental health. Sokolovsky et al. (2021) reported a decrease in the frequency of smoking and vaping among students in early Spring 2020.

Once the early stage of the pandemic had passed, different countries adopted diverging approaches depending on the number of COVID cases as well as economic and political considerations (Ibrahim, Binofai \& Alshamsi, 2020; OECD, 2020). Some countries went through extended lockdowns while others decided against further restrictions or used shorter complete or partial lockdowns only. The United States was a mirror image of what happened around the world; some states imposed extended lockdowns that included closure of schools and universities, others decided to open up everything as soon as possible (Treisman, 2020). The differences in when and to what extent countries were affected by the second and third wave of the pandemic and which approach they adopted are the main reasons why there are only a few longitudinal studies on the impact on students' mental health and health behavior beyond the initial stage so far. Savage at al. (2021) investigated the impact on mental health and physical activity of university students in the UK nine months into the pandemic. Study participants still reported reduced mental well-being and physical activity, and increased perceived stress and sedentary behavior in October 2020. Collecting data from graduating students at a university in Ethiopia in November 2020, Mekonen et al. (2021) found that one-fifth of students reported stress, and two-fifths anxiety and depression. 
122 Our research project on student health behaviors and habits started in Spring 2018 and, therefore,

123 adding survey data from Fall 2020 and Spring 2021 enabled us to assess the impact COVID-

124 related restrictions had on our students beyond the initial phase. Although the situation in Florida

125 and at our university was different from what students in other countries and at other institutions

126 of higher education experienced, the results are an important contribution to our understanding of

127 how prolonged extreme events can impact students' behaviors, habits, and mental and emotional

128 health.

\section{METHODS}

130 Data for this article were collected between April 2018 and April 2021 using two anonymous

131 online surveys. Each Summer and Fall semester, emails were sent to students enrolled in courses

132 that are taken by students from different colleges and majors, such as 'Statistical methods' or

133 'Introduction into Psychology', inviting them to participate in our survey. The total number of

134 students invited per semester was approximately 2,000-2,500. The number of students

135 participating in the survey per semester usually ranged from 150-250, i.e., the response rate was

136 in the range of $6-10 \%$.

137 The first survey, used from April 2018 to February 2020, consisted of five groups of questions

138 around health and wellness (see Appendix 1); the survey was described previously (Reuter \&

139 Forster, 2021). Some of the data collected, but unrelated to the current research, has been

140 published elsewhere (Reuter, Forster \& Brister, 2020; Reuter \& Forster, 2021).

141 After the onset of the COVID-19 pandemic and the introduction of pandemic-related restrictions

142 nationally, locally, and at Florida Gulf Coast University (FGCU), the survey was modified in

143 order to capture the impact these restrictions had on students' health behaviors and habits as well

144 as their mental and emotional health (see Appendix 2).

145 Although the study used a repeated cross-sectional survey design, the data collected did not

146 consists of independent data sets as students may have participated more than once during

147 different semesters. Thus, our study contained repeated cross-sectional and panel elements.

148 Both surveys were approved by the Institutional Review Board (IRB) at FGCU prior to sending

149 email invitations to students (IRB 2018-17). The first page of the survey consisted of an

150 approved online survey consent form; in other words, consent was obtained. Participation was 
151 voluntary and participants did not receive any compensation or any other direct or indirect

152 benefit from the university or us.

153 COVID-19 related restrictions in Florida and at FGCU

154 Florida went into a 30 day stay-at-home order in April 2020, with Phase 1 reopening already

155 taking effect by mid-May for all counties (DeSantis, 2020). Phase 2, which included restaurants

156 operating at $50 \%$, gyms at full capacity with social distancing in place, gatherings expanded to a

15750 person limit, and employers beginning to develop a plan to bring workers back, was put in

158 place by mid-June 2020. Phase 3, which began in September 2020, removed many of the

159 restrictions left from phase 2, and also allowed non-essential travel, full capacity at restaurants

160 and bars, and gyms and recreation centers operating at full capacity without social distancing

161 enforced. The State University System of Florida Blueprint for Reopening Campuses for Fall

162 Semester 2020 focused on promoting a healthy campus and community environment while still

163 offering successful academic program delivery (University System of Florida, 2020).

164 FGCU is a regional university located in Southwest Florida with a student population of about

165 15,000 undergraduate and graduate students (Florida Gulf Coast University, 2021a). Ninety-

166 seven percent of students are from Florida and half of them come from Southwest Florida. Six

167 out of ten students identify as White, slightly more than one-fifth as Hispanic, and one in twelve

168 as Black. Students of Asian origin make up 3.3\% of the student body, and Native American

169 students account for $0.9 \%$ (Florida Gulf Coast University, 2021a). FGCU's COVID plan for the

170 Fall semester 2020 was finalized in early June (Florida Gulf Coast University, 2020a). Many of

171 the new rules impacted students' lives, including limited shuttle routes and seating on buses,

172 mask requirements everywhere on campus, and enforced social distancing. Additional measures

173 included restrictions and limitations on intramural sports, closure of indoor and outdoor

174 recreational facilities, and group events and meetings capped at 50\%. All housing units were

175 adjusted for single bedroom occupancy, and class and classroom sizes were reduced (about 38\%

176 of campus space utilized at one time with 50\% of classroom capacity). Slightly more than 50\%

177 of classes offered were online classes ( $28 \%$ online asynchronous, $24 \%$ online synchronous),

178 approximately $45 \%$ of classes were taught in the classroom, and less than $4 \%$ were scheduled as

179 hybrid classes. The COVID-19 plan for Spring and Summer 2021 was an extension of the plan

180 for Fall 2020 (Florida Gulf Coast University, 2020b). 
181

182

183

184

185

186

187

188

189

190

191

192

193

194

195

196

197

198

199

200

201

202

203

204

205

206

207

208

209

210

211

\section{Data analysis}

Due to the voluntary nature of the survey, sample sizes vary for different analyses, but are included in the results description or tables. Data are presented as means with standard deviation for questions with quantitative answers and as a percentage of the total participant pool, or a portion of this pool, for questions with categorical answer options.

We used Pearson Chi-Square Tests, Fisher's Exact Test, and Kruskall-Wallis Rank Sums Tests to examine differences between the pre-COVID and COVID survey group. The dependent variable in all tests was survey group (a categorical variable with two options: pre-COVID and COVID). Independent variables are listed in Table 1 below.

We used the Benjamini-Hochberg Procedure (with a false discovery rate of 5\%) to determine significance due to the number of statistical analyses performed. Using this approach, tests with a p-value $<0.0171$ are considered significant. Statistical analyses were performed using JMP software program Version 16 (JMP®; SAS Institute Inc., Cary, NC, USA).

$>$ Table $1<$

\section{RESULTS}

\section{Demographic characteristics of respondents}

After excluding responses that indicated an age of less than 18 years or did not provide an age, we were left with 721 responses for the pre-COVID survey and 506 responses for the COVID survey (Table 2). There was no difference between the two survey groups in the proportion of freshmen, sophomores, juniors, seniors, or other students (graduate, non-degree seeking, and second-degree seeking students) (Pearson Chi-Square Test, Chi-square $=2.637, \mathrm{DF}=5, \mathrm{p}=$ 0.76). There was, however, a change in living circumstances between the two survey groups (Pearson Chi-Square Test, Chi-square $=22.239, \mathrm{DF}=3, \mathrm{p}<0.0001$ ), with more students living at home and fewer students living on-campus in the COVID group. In both survey groups, female respondents outnumbered male respondents, and the COVID group had proportionally more female respondents than the pre-COVID group (Fisher's Exact Test, $p=0.0088$ ), even though the student body at the university consists of $52 \%$ female and $48 \%$ male students (Florida Gulf Coast University; 2021b).

$>$ Table $2<$ 


\section{Sleeping habits}

213 The proportion of respondents reporting average hours of sleep over the past seven days differed

214 between the pre-COVID group and the COVID group (Pearson Chi-Square Test, Chi-square $=$

$21529.890, \mathrm{DF}=6, \mathrm{p}<0.0001)$. The percentage of respondents reporting to sleep eight hours or

216 more was almost 50\% higher for the COVID group (30.6\%) compared with the pre-COVID

217 group $(21.1 \%)$.

218 The time when respondents went to bed also changed between the pre-COVID group and the

219 COVID group, as the proportion of respondents reporting an average bedtime differed between

220 the pre-COVID and the COVID group (Pearson Chi-Square Test, Chi-square $=22.942, \mathrm{DF}=4, \mathrm{p}$

$221<0.0001)$. In the COVID group, more respondents reported going to sleep after 2am and fewer

222 students went to bed between $10 \mathrm{pm}$ and $2 \mathrm{am}$.

\section{Working}

224 There was no difference in the proportion of respondents that indicated they worked zero hours

225 per week between the pre-COVID group (45.3\%) and the COVID group. (50.3\%; Pearson Chi-

226 Square Test, Chi-square $=3.452, \mathrm{DF}=1, \mathrm{p}=0.0632$ ). Among respondents that worked at least

227 one hour per week on average ( $n=395$ in the pre-COVID group; $n=251$ in the COVID group),

228 there was also no difference in the proportion of respondents reporting average hours worked.

\section{Physical activity}

230 There were differences in the self-reported physical activity between the two survey groups

231 (Table 3). Respondents in the COVID group reported a lower average number of days of

232 physical activity per week $(2.7 \pm 2.2$, mean \pm std. dev $)$ than respondents in the pre-COVID group

$233(3.1 \pm 2.2$, mean \pm std. dev) (Kruskal-Wallis Rank Sums Test, Chi-square $=9.3421, \mathrm{DF}=1, \mathrm{p}=$

234 0.0022). Respondents from the COVID group reported less physical activity with more students

235 not being physically active at all (21.4\% vs. 16.6\% pre-COVID) and fewer students being

236 physically active on six or seven days (11.6\% vs. $18.2 \%$ pre-COVID). Respondents in the

237 COVID group also reported a lower average number of days of strength training per week (1.7 \pm

2382.1 , mean \pm std. dev) than respondents in the pre-COVID group $(1.9 \pm 2.1$, mean \pm std. dev $)$

239 (Kruskal-Wallis Rank Sums Test, Chi-square $=2.2429, \mathrm{DF}=1, \mathrm{p}=0.1342$.

\section{Eating habits}


241 There were no differences in the consumption of vegetables and fruits between the two survey

242 groups (Table 3). The proportion of respondents reporting frequency of vegetable consumption

243 over a 7-day period did not differ between the pre-COVID group and the COVID group (Pearson

244 Chi-Square Test, Chi-square $=1.591, \mathrm{DF}=4, \mathrm{p}=0.8104)$. The proportion of respondents

245 reporting frequency of fruit consumption over a 7-day period also did not differ between the pre-

246 COVID group and the COVID group (Pearson Chi-Square Test, Chi-square $=2.726, \mathrm{DF}=4, \mathrm{p}=$

$2470.6046)$.

248 However, respondents in the COVID group reported a lower average number of days per week

249 they ate breakfast $(3.7 \pm 2.7$, mean \pm std. dev $)$ compared with respondents in the pre-COVID

250 group $(4.1 \pm 2.5$, mean \pm std. dev) (Kruskal-Wallis Rank Sums Test, Chi-square $=7.7713, \mathrm{DF}=$

$2511, p=0.0053)$. Students in the COVID group were twice as likely to skip breakfast as students in

252 the pre-COVID group (19.0\% vs. $9.8 \%)$.

253 The proportion of respondents who reported eating fast food at least once in the past seven days

254 did not differ in the COVID group (78.3\%) from the pre-COVID group $(72.3 \%)$ ((Pearson Chi-

255 Square Test, Chi-square $=4.513, \mathrm{DF}=1, \mathrm{p}=0.0336$ ). Additionally, for those that reported

256 eating fast food, the amount of times fast food was consumed over a 7-day period did not differ

257 between the pre-COVID group and the COVID group (Pearson Chi-Square Test, Chi-square =

$2584.417, \mathrm{DF}=3, \mathrm{p}=0.2198)$.

259 There were no differences in the consumption of cups of caffeinated coffee between the pre-

260 COVID and the COVID group (Pearson Chi-Square Test, Chi-square $=3.219, \mathrm{DF}=1, \mathrm{p}=$

261 0.0728). The proportion of respondents who reported drinking caffeinated coffee at least once in

262 the past seven days did not differ between the two groups either. Among those who drank coffee

263 at least once, the proportion of respondents reporting frequency of caffeinated coffee

264 consumption over a 7-day period did not differ between the two groups Pearson Chi-Square Test,

265 Chi-square $=5.229, \mathrm{DF}=3, \mathrm{p}=0.1558$ ).

$266>$ Table $3<$

267 Online activity

268 The proportion of respondents reporting the amount of time spent watching television or reading

269 online over a 7-day period differed between the pre-COVID and the COVID group (Pearson Chi-

270 Square Test, Chi-square $=23.071, \mathrm{DF}=6, \mathrm{p}=0.0008)$. Almost one-quarter of respondents from 
271 the COVID group (23.8\%) spent five hours or more online watching TV or movies per day

272 compared with one in seven respondents of the pre-COVID group (14.6\%).

273 Likewise, there was a difference between the two survey groups in the proportion of respondents

274 reporting the amount of time spent playing video games or using an electronic device for things

275 that are not school work over a 7-day period (Pearson Chi-Square Test, Chi-square $=36.963, \mathrm{DF}$

$276=6, \mathrm{p}<0.0001)$.

\section{Vaping, alcohol, and marijuana}

278 Respondents in the COVID group reported vaping on a higher average number of days per week

$279(2.9 \pm 3.2$ days per week, mean \pm std. dev $)$ than respondents in the pre-COVID group $(1.6 \pm 2.5$

280 days per week) (Kruskal-Wallis Rank Sums Test, Chi-square $=11.3200$, DF $=1, \mathrm{p}=0.0008$ ).

281 Nonetheless, vaping did not become more prevalent overall during the COVID pandemic; $35.5 \%$

282 of survey respondents from the pre-COVID group and $37.1 \%$ of respondents from the COVID 283 group had vaped before. Conversely, one in three respondents from the COVID group (34.6\%)

284 reported having vaped daily compared with one in seven respondents from the pre-COVID group $285(15.7 \%)$.

286 The proportion of respondents who reported drinking alcohol on at least one day in the last 30 287 days was lower in the COVID group (50.5\%) compared with the pre-COVID group (75.0\%) 288 (Pearson Chi-Square Test, Chi-square $=65.505, \mathrm{DF}=1, \mathrm{p}<0.0001$ ). However, of those that did 289 drink at least one day in the prior month, the number of days on which alcohol was consumed 290 did not differ between the pre-COVID group and the COVID group.

291 Respondents in the COVID group reported using marijuana on a higher average number of days 292 per week $(1.5 \pm 2.4$ days per week, mean \pm std. dev $)$ than respondents in the pre-COVID group 293 (1.0 \pm 2.3 days per week; Kruskal-Wallis Rank Sums Test, Chi-square $=15.6320$, DF $=1, p<$ 294 0.0001). Additionally, more respondents from the COVID group than the pre-COVID group had 295 used marijuana during the past seven days (20.2\% vs. 15.0\%) and more than twice as many of 296 them had used every day during that time (10.0\% vs. $4.2 \%)$.

\section{Mental/emotional health}

298 A higher proportion of respondents from the COVID group reported having serious difficulty 299 concentrating, remembering, or making decisions compared with the pre-COVID group (47.2\% 300 vs. 22.4\%; Pearson Chi-Square Test, Chi-square $=77.283, \mathrm{DF}=1, \mathrm{p}<0.0001)$. There was also 
301 an increase in the proportion of respondents in the COVID group who had felt so sad or hopeless

302 almost every day for two weeks or more in a row that they stopped doing some usual activities

303 (44.6\% in the COVID group vs. $37.6 \%$ in the pre-COVID group; Pearson Chi-Square Test, Chi-

304 square $=5.686, \mathrm{DF}=1, \mathrm{p}=0.0171)$.

305 Conversely, there was no change in the proportion of respondents who had seriously considered 306 committing suicide (12.2\% in the COVID group vs. $13.3 \%$ in the pre-COVID group; Pearson 307 Chi-Square Test, Chi-square $=0.259, \mathrm{DF}=1, \mathrm{p}=0.6108)$. Among those who had considered 308 committing suicide, there was no change between the survey groups in the number of times they 309 had considered attempting suicide (Pearson Chi-Square Test, Chi-square $=1.399, \mathrm{DF}=3, \mathrm{p}=$ 310 0.7057). In regards to acting on thoughts about suicide, a similar proportion of students in both 311 survey groups planned out their suicide attempt (47\% in the pre-COVID group; $62 \%$ in the 312 COVID group; Pearson Chi-Square Test, Chi-square $=2.762, \mathrm{DF}=3, \mathrm{p}=0.0965)$. Of these, a 313 similar proportion (18\% in the pre-COVID group and 22\% in the COVID group) actually did 314 attempt suicide (Pearson Chi-Square Test, Chi-square $=0.229, \mathrm{DF}=1, \mathrm{p}=0.6324$ ).

315 The survey used during the COVID pandemic from November 2020 to April 2021 contained 316 additional questions to gather information on students' emotional state (Table 4). One-quarter of

317 respondents indicated not feeling safe on campus during COVID, and three-quarters of

318 participating students said that they had craved human interaction over the previous six months.

319 More than half of respondents felt that their mental/emotional health had been impacted by the

320 lack of social events or the switch to virtual (online) teaching. Two-thirds or more of respondents

321 also expressed that they felt less connected to their peers and less motivated in their studies than 322 in previous semesters.

324 Furthermore, participants were also invited to select up to ten words that described their 325 emotional state from a list of thirty-nine words (Table 5). Overall 504 students participated, 326 although not all respondents selected a full set of ten words. The six emotions selected by more 327 than $50 \%$ of respondents were anxious, stressed, overwhelmed, disconnected, tired, and fatigued.

328 At the other end of the rankings, the six emotions selected by the smallest percentage of 329 respondents were sanguine, serene, upbeat, inspired, peaceful, and frightened. 


\section{DISCUSSION}

333 The purpose of this research project was to study the impact prolonged restrictions related to 334 COVID had on students' health behavior as well as their mental and emotional health. Because 335 the situation was unique in recent history, the results add to our general understanding of how 336 extreme events impact people's physical and mental health. The longitudinal data of our study 337 show a significant difference for some student behaviors and habits, such as sleeping habits, 338 physical activity, breakfast consumption, time spent online or playing video games, vaping, and marijuana use, during the COVID pandemic compared with pre-COVID data. While study respondents also reported a significant increase in difficulty concentrating, remembering, or making decisions, as well as being impacted by feeling sad or hopeless, there was no increase in the proportion of respondents considering, planning or attempting suicide during COVID. The cross-sectional data from the survey administered during the COVID pandemic illuminate the negative effect of the overall situation and the restrictions on students' mental and emotional well-being. While we have no pre-COVID data to compare with, it is doubtful that three-quarters of respondents would have craved human interaction during normal times. It is also telling that the six words describing emotions selected by half of respondents or more describe negative emotional states. On the other hand, respondents in our survey were not more worried about their safety on campus during COVID. Data from the American College Health Association Nation College Health Assessment III (2020) show that prior to COVID one in seven male students and one in four female students did not feel safe on campus during daytime hours, and one in two male and four in five female students did not feel safe on campus at night.

The change in the proportion of students living at home can be attributed to a number of factors. Although more than half of respondents $(51.3 \%)$ were enrolled in at least one in-person face-2face class, most of them took mainly online classes. Living at home and commuting once or twice per week to campus was preferable at a time where many families experienced economic hardship. Plus, students living at home faced fewer restrictions on social interactions and outside activities than students living on campus, making living at home more attractive.

The fact that there is no difference in the proportion of students working and in the number of hours worked is a reflection of the overall approach to handling the pandemic by the state of 
362 staying up later during the COVID pandemic do not point at a loss of sleep quality. With fewer

363 students having to get up in the morning to go to campus or to get to class, one can understand 364 that there is a tendency to stay up late and sleep longer. Thus, our findings do not confirm the 365 loss of sleep quality reported by Deng et al. (2021), Du et al. (2021), Firkley, Sheinfil \& Woolf366 King (2021), Giuntella et al. (2021), and Maher et al. (2021) during the early (lockdown) stage in 367 different countries. The study by Moriarty et al. (2021) was conducted in the US in June/July 3682020 and its results are similar to ours. Evans et al. (2021) also found a shift to staying up late in 369 their study of undergraduate psychology students at a UK university.

370 The same reasons, i.e., not having to get up in the morning, as well as the limitations on social 371 activities, may explain shifts in sleeping patterns and why respondents reported more screen 372 time during the COVID pandemic (i.e., spending more time online reading or watching TV or 373 movies, and playing video or computer games). Giuntella et al. (2021) also reported an increase 374 in screen time. This increase can also be considered increased sedentary behavior and confirms 375 similar findings reported by Savage et al. (2020) and Bertrand et al. (2021) in the early pandemic 376 stage as well as in the longitudinal study by Savage et al. (2021).

377 The decline in physical activity reported by our study respondents from pre-COVID to COVID is 378 in line with results for the early pandemic published by Savage et al. (2020), Bertrand et al.

379 (2021), Giuntella et al. (2021), López-Valenciano (2021), and Wilson et al. (2021). The 380 longitudinal study by Savage et al. (2021) also reported a decrease in physical activity among 381 university students in the UK nine months into the pandemic.

382 While we found a negative impact on breakfast and fast-food consumption, this should not be 383 understood as a reduction in the quality of the diet along the line of results reported by Bertrand et al. (2021) and Du et al. (2021). These changes may be due to students' changed living arrangements and sleeping habits. For example, they may skip breakfast because they sleep longer or may consider the first meal of the day to be lunch if they sleep in. Likewise, because more of them live at home without a meal plan, they may be prone to picking up fast food on the way to or from work and campus.

389 The increase in vaping, alcohol consumption, and marijuana use from the pre-COVID to the 390 COVID period aligns with the increases found in studies during the early pandemic (Bertrand et al., 2021; Du et al, 2021; Evans et al., 2021; Firkley, Sheinfil \& Woolf-King, 2021). Contrary to 
392 these studies and ours, the retrospective study by Sokolovsky et al. (2021) found that the

393 frequency of smoking and vaping decreased after students went into lockdown.

394 The longitudinal as well as the cross-sectional survey data in our study show an increase in stress

395 levels, anxiety, and depression during the COVID period, and thus, broadly confirm studies from

396 the early pandemic involving college and university students in the US (Holingue et al., 2020;

397 Jeffery \& Bauer, 2020; Kecojevic et al., 2020; Wang et al., 2020; Hawes et al., 2021) and other

398 countries (Essadek \& Rabeyron, 2020; Kaparounaki et al., 2020; Wathelet et al., 2020; Baloch et

399 al., 2021). Fortunately, our data show that the proportion of students considering, planning, and

400 attempting suicide did not increase during the pandemic. This was also reported by Pirkis et al.

401 (2021), who analyzed data from 21 countries around the world in Fall 2020 and found no

402 evidence for an increase in suicide rates compared with pre-pandemic levels.

403 A major strength of our study is having data from before the COVID pandemic through the later

404

405

406

407

408

409

410

411

412

413

414

415

416

417

418

419

420

421

part of the pandemic. Even though the data are not truly longitudinal, this enabled us to compare how students' health behaviors and habits changed or did not change during the course of the pandemic, and how students coped with the extended period of stress and uncertainty. The main limitations of our study were participant selection and reliance on self-reported health behaviors and habits. Even though students from all colleges across the university were invited to participate, the overall response rate was in the range of $6-10 \%$ only. We received almost $80 \%$ of responses from female students, whereas the FGCU student body has only slightly more than $50 \%$ female students (Florida Gulf Coast University, 2021b). Additionally, we cannot rule out that students may have participated more than once during the same semester.

Every survey has to question whether respondents may have intentionally or unintentionally provided incorrect information, especially when behaviors are involved that are not legal or socially acceptable. For example, the legal drinking age in Florida is 21 years and, therefore, students under 21 who report drinking alcohol admit to breaking the law. The same applies to the use of recreational drugs. Also, some of the health behaviors and habits included in the survey were not well defined and respondents may have interpreted them differently. For instance, respondents may have considered walking to class as being physically active. We are also aware that some questions could be considered overlapping; for example, the questions relating to time spent watching TV, movies, or reading news online, and time spent playing video or computer 
422 games. We also failed to include a question relating to time spent on social media in general in

423 our survey, leading to responses indicating that students had not spent much time online overall.

424 However, because we looked at a change from pre-COVID to COVID, this mistake did not

425 impact our results negatively.

426 One also has to point out that Florida had very limited restrictions compared with other states 427 and countries, which led to our respondents being able to continue to work almost as much as 428 before the pandemic, for example. This, in turn, buffered the economic impact on students and 429 their families as well as on students' emotional and mental health. Likewise, our university is 430 located in an area with an above average median household income, $90 \%$ percent or more of 431 household have a computer, and $80 \%$ or more broadband internet connection (United States 432 Census Bureau, 2021).

433 Following how students' behaviors and their emotional health change during academic year $4342021 / 2022$ will be very interesting. At the moment, the plan for Florida and our institution is to 435 go back to pre-pandemic conditions as far as teaching, restrictions on class sizes, meetings, and 436 indoors and outdoors social events (all removed), face masks (not required anymore), and social 437 distancing (not required anymore) are concerned. Unfortunately, because the State of Florida 438 made it illegal to ask students, faculty, or staff to report their vaccination status (although the 439 information can be provided voluntarily) or to require them to get vaccinated, what will or may 440 happen is less certain than one may think. Among our survey respondents, only 64.2\% (194 of 441302 responses) indicated that the chances of them getting a COVID vaccination was $70 \%$ or 442 higher, while more than one-quarter put the chances of them getting vaccinated at $30 \%$ or less 443 (26.8\%; 81 of 302 responses). These data indicate that our student population may still be 444 vulnerable to COVID for some time, especially now that more contagious virus variants become 445 dominant. By Spring 2022, seniors participating in our survey will have been freshmen or 446 sophomores pre-pandemic and juniors during the pandemic, allowing us to chart their journey 447 longitudinally.

\section{CONCLUSIONS}

449 The longitudinal data collected and analyzed indicate that the impact of COVID-related 450 restrictions on students' behaviors and habits as well as their mental and emotional health was

451 less severe than one would have expected based on studies during the early stage of the 
452 pandemic. While some behaviors and habits changed during the COVID pandemic compared

453 with the pre-COVID period, the changes were not substantial overall and most students' lives

454 outside of studying went on with little change. Likewise, our study did not find an increase in the

455 proportion of respondents considering, planning or attempting suicide during COVID, although

456 study participants reported a significant increase in difficulty concentrating, remembering, or

457 making decisions, as well as being impacted by feelings of sadness or hopelessness. Also, the

458 cross-sectional data from our survey make the negative effect of the overall situation and the

459 restrictions on students' mental and emotional well-being evident.

460 The impact of this pandemic will unquestionably be long-lasting and, thus, necessitate future

461 investigations. Even though some countries and states in the US, including Florida, have dropped

462 almost all restrictions and more or less plan on business as usual for schools, colleges, and

463 universities for Fall 2021 and beyond, new waves of high infection rates caused by different

464 SARS-CoV-2 variants may force a change of course. Studying how students react to even more

465 or new restrictions and whether those who were impacted by the first round of restrictions will

466 handle the situation better than those who enter higher education now, will be an interesting

467 focus for further research.

\section{REFERENCES}

469 American College Health Association. 2020. American College Health Association-National

470 College Health Assessment III: Reference Group Executive Summary Fall 2020. Silver

471 Spring, MD: American College Health Association; Available at

472 https://www.acha.org/documents/ncha/NCHA-

473 III_Fall_2020_Reference_Group_Executive_Summary.pdf.

474 Aucejo EM, French J, Araya MPU, Zafar B. 2020. The impact of COVID-19 on student

475 experiences and expectations: Evidence from a survey. Journal of Public Economics Volume

476 191, 2020, 104271. DOI 10.1016/j.jpubeco.2020.104271.

477 Baloch GM, Sundarasen S, Chinna K, Nurunnabi M, Kamaludin K, Khoshaim HB, Hossain

478 SFA, AlSukayt A. 2021. COVID-19: exploring impacts of the pandemic and lockdown on

479 mental health of Pakistani students. PeerJ 9:e10612 DOI 10.7717/peerj.10612. 
480

481

482

483

484

485

486

487

488

489

490

491

492

493

494

495

496

497

498

499

500

501

502

503

504

505

506

507

508

Bertrand L, Shaw KA, Ko J, Deprez D, Chilibeck PD, Zello GA. 2021. The impact of the coronavirus disease 2019 (COVID-19) pandemic on university students' dietary intake, physical activity, and sedentary behaviour. Applied Physiology, Nutrition, and Metabolism. 2021 Mar;46(3):265-272. DOI 10.1139/apnm-2020-0990.

Castañeda-Babarro A, Arbillaga-Etxarri A, Gutiérrez-Santamaría B, Coca A. 2020. Physical activity change during COVID-19 confinement. International Journal of Environmental Research and Public Health. 2020;17(18):6878. DOI 10.3390/ijerph17186878.

Deng J, Zhou F, Hou W, Silver Z, Wong CY, Chang O, Drakos A, Zuo QK, Huang E. 2021. The prevalence of depressive symptoms, anxiety symptoms and sleep disturbance in higher education students during the COVID-19 pandemic: A systematic review and meta-analysis. Psychiatry Research. 2021 Mar 9;301:113863. DOI 10.1016/j.psychres.2021.113.

DeSantis R. 2020. 2020 Executive Orders. Available at https://www.flgov.com/2020-executiveorders.

Du C, Zan MCH, Cho MJ, Fenton JI, Hsiao PY, Hsiao R, Keaver L, Lai CC, Lee H, Ludy MJ, Shen W, Swee WCS, Thrivikraman J, Tseng KW, Tseng WC, Doak S, Folk SYL, Tucker RM. 2021. The effects of sleep quality and resilience on perceived stress, dietary behaviors, and alcohol misuse: A mediation-moderation analysis of higher education students from Asia, Europe, and North America during the COVID-19 pandemic. Nutrients. 2021;13(2):442. DOI $10.3390 /$ nu13020442.

Essadek A, Rabeyron T. 2020. Mental health of French students during the Covid-19 pandemic. Journal of Affective Disorders, Volume 277, Pages 392-393. DOI 10.1016/j.jad.2020.08.042.

Evans S, Alkan E, Bhangoo JK, Tenenbaum H, Ng-Knight T. 2021. Effects of the COVID-19 lockdown on mental health, wellbeing, sleep, and alcohol use in a UK student sample. Psychiatry Research. 2021 Apr;298:113819. DOI 10.1016/j.psychres.2021.113819.

Firkey MK, Sheinfil AZ, Woolf-King SE. 2021. Substance use, sexual behavior, and general well-being of U.S. college students during the COVID-19 pandemic: A brief report. Journal of American College Health. 2021 Feb 12:1-7. DOI 10.1080/07448481.2020.1869750.

Florida Gulf Coast University (2021a). About FGCU. Available at https://www.fgcu.edu/about/. Accessed June 21, 2021. 
509 Florida Gulf Coast University (2021b). About FGCU. Fast facts. Available at

510 https://www.fgcu.edu/about/fastfacts. Accessed June 21, 2021.

511 Florida Gulf Coast University. (2020a). Fall 2020 COVID-19 Plan. Available at

512 https://www.fgcu.edu/coronaupdate/files/bot-approved-fgcu-fall-2020-covid19-plan-060920-

513 ada.pdf.

514 Florida Gulf Coast University. (2020b). Spring and Summer 2021 COVID-19 Plan. Available at

515 https://www.fgcu.edu/coronaupdate/files/spring-summer-2021-covid-19-plan-bot-

516 approved121020-ada.pdf.

517 Fruehwirth JC, Biswas S, Perreira KM. 2021. The Covid-19 pandemic and mental health of first-

518 year college students: Examining the effect of Covid-19 stressors using longitudinal data.

$519 \quad$ PLoS One. 2021 Mar 5;16(3):e0247999. DOI 10.1371/journal.pone.0247999.

520 Gillis A, Krull LM. 2020. COVID-19 remote learning transition in Spring 2020: Class structures, 521 student perceptions, and inequality in college courses. Teaching Sociology. 2020;48(4):283522 299. DOI 10.1177/0092055X20954263.

523 Giuntella O, Hyde K, Saccardo S, Sadoff S. 2021. Lifestyle and mental health disruptions during 524 COVID-19. Proceedings of the National Academy of Sciences of the United States of $525 \quad$ America. 2021 Mar 2;118(9):e2016632118. DOI 10.1073/pnas.2016632118.

526 Hawes MT, Szenczy AK, Klein DN, Hajcak G, Nelson BD. 2021. Increases in depression and 527 anxiety symptoms in adolescents and young adults during the COVID-19 pandemic.

$528 \quad$ Psychological Medicine 2021:1-9. DOI 10.1017/S0033291720005358.

529 Holingue C, Kalb LG, Riehm KE, Bennett D, Kapteyn A, Veldhuis CB, Johnson RM, Fallin 530 MD, Kreuter F, Stuart EA, Thrul J. 2020. Mental distress in the United States at the beginning 531 of the COVID-19 pandemic. American Journal of Public Health. 2020 Nov;110(11):1628532 1634. DOI 10.2105/AJPH.2020.305857.

533 Ibrahim MD, Binofai FAS, MM Alshamsi R. 2020. Pandemic response management framework 534 based on efficiency of COVID-19 control and treatment. Future Virology. 2020;10.2217/fvl535 2020-0368. DOI 10.2217/fvl-2020-0368. 
536 Jeffery KA, Bauer CF. 2020. Students' responses to emergency remote online teaching reveal

537 critical factors for all teaching. Journal of Chemical Education 97 (9), 2472-2485. DOI

$538 \quad 10.1021 /$ acs.jchemed.0c00736.

539 Kaparounaki CK, Patsali ME, Mousa DV, Papadopoulou EVK, Papadopoulou KKK,

540 Fountoulakis KN. 2020. University students' mental health amidst the COVID-19 quarantine

541 in Greece. Psychiatry Research. 2020 Aug;290:113111. DOI

$542 \quad 10.1016 /$ j.psychres.2020.113111.

543 Kecojevic A, Basch CH, Sullivan M, Davi NK. 2020. The impact of the COVID-19 epidemic on 544 mental health of undergraduate students in New Jersey, cross-sectional study. PLoS ONE 545 15(9): e0239696. DOI 10.1371/journal.pone.0239696.

546 López-Valenciano A, Suárez-Iglesias D, Sanchez-Lastra MA, Ayán C. 2021. Impact of COVID54719 pandemic on university students' physical activity levels: An early systematic review. $548 \quad$ Frontiers in Psychology. 2021;11:624567. DOI 10.3389/fpsyg.2020.624567.

549 Maher JP, Hevel DJ, Reifsteck EJ, Drollette ES. 2021. Physical activity is positively associated 550 with college students' positive affect regardless of stressful life events during the COVID-19 $551 \quad$ pandemic. Psychology of Sport and Exercise. 2021;52:101826. DOI

$552 \quad 10.1016 /$ j.psychsport.2020.101826.

553 Martinez A, Nguyen S. 2020. The impact of Covid-19 on college student well-being. The

554 Healthy Minds Network American College Health Association. Available at 555 http://hdl.handle.net/10919/99741.

556 Mekonen EG, Workneh BS, Ali MS, Muluneh NY. 2021. The psychological impact of COVID55719 pandemic on graduating class students at the University of Gondar, Northwest Ethiopia. 558 Psychology Research and Behavior Management. 2021 Feb 9;14:109-122. DOI $559 \quad 10.2147 /$ PRBM.S300262.

560 Moriarty T, Bourbeau K, Fontana F, McNamara S, Pereira da Silva M. 2021. The relationship 561 between psychological stress and healthy lifestyle behaviors during COVID-19 among 562 students in a US Midwest university. International Journal of Environmental Research and 563 Public Health. 2021, 18, 4752. DOI 10.3390/ijerph18094752. 
564 Ochnik D, Rogowska AM, Kuśnierz C, Jakubiak M, Schütz A, Held MJ, Arzenšek A, Benatov J, 565 Berger R, Korchagina EV, Pavlova I, Blažková I, Konečná Z, Aslan I, Çınar O, Cuero-Acosta 566 YA, Wierzbik-Strońska M. 2021. A comparison of depression and anxiety among university 567 students in nine countries during the COVID-19 pandemic. Journal of Clinical Medicine. 568 2021 Jun 29;10(13):2882. DOI 10.3390/jcm10132882.

569 OECD. 2020. The territorial impact of COVID-19: Managing the crisis across levels of 570 government. Available at https://www.oecd.org/coronavirus/policy-responses/the-territorialimpact-of-covid-19-managing-the-crisis-across-levels-of-government-d3e314e1/.

572

573

574

575

576

577

578

579

580

581

582

583

584 585 586

587 588

589

590

591

592

593

Pirkis J, John A, Shin S, DelPozo-Banos M, Arya V, Analuisa-Aguilar P, Appleby L, Arensman

$$
\text { E, Bantjes J, Baran A, Bertolote JM, Borges G, Brečić P, Caine E, Castelpietra G, Chang S, }
$$
Colchester D, Crompton D, Curkovic M, Deisenhammer EA, Du C, Dwyer J, Erlangsen A, Faust JS, Fortune S, Garrett A, George D, Gerstner R, Gilissen R, Gould M, Hawton K, Kanter J, Kapur N, Khan M, Kirtley OJ, Knipe D, Kolves K, Leske S, Marahatta K, Mittendorfer-Rutz E, Neznanov N, Niederkrotenthaler T, Nielsen E, Nordentoft M, Oberlerchner H, O’Connor RC, Pearson M, Phillips MR, Platt S, Plener PL, Psota G, Qin P, Radeloff D, Rados C, Reif A, Reif-Leonhard C, Rozanov V, Schlang C, Schneider B, Semenova N, Sinyor M, Townsend E, Ueda M, Vijayakumar L, Webb RT, Weerasinghe M, Zalsman G, Gunnell D, Spittal MJ. 2021. Suicide trends in the early months of the COVID-19 pandemic: An interrupted time-series analysis of preliminary data from 21 countries. The Lancet Psychiatry. 2021; 8:579-88. DOI 10.1016/S2215-0366(21)00091-2.

Reuter PR, Forster BL, Brister SR. 2020. The influence of eating habits on the academic performance of university students. The Journal of American College Health, DOI 10.1080/ 07448481.2020 .1715986$.

Reuter PR, Forster BL. 2021. Student health behavior and academic performance. PeerJ 9:e11107 DOI 10.7717/peerj.11107.

Romero-Blanco C, Rodríguez-Almagro J, Onieva-Zafra MD, Parra-Fernández ML, PradoLaguna MDC, Hernández-Martínez A. 2020. Physical activity and sedentary lifestyle in university students: Changes during confinement due to the COVID-19 pandemic. International Journal of Environmental Research and Public Health. 2020;17(18):6567. 2020 Sep 9. DOI 10.3390/ijerph17186567. 
594 Saddik B, Hussein A, Sharif-Askari FS, Kheder W, Temsah MH, Koutaich RA, Haddad ES, Al595 Roub NM, Marhoon FA, Hamid Q, Halwani R. 2020. Increased levels of anxiety among 596 medical and non-medical university students during the COVID-19 pandemic in the United 597 Arab Emirates. Risk Management and Healthcare Policy. 2020 Nov 3;13:2395-2406. DOI $598 \quad 10.2147 /$ RMHP.S273333.

599 Savage MJ, Hennis PJ, Magistro D, Donaldson J, Healy LC, James RM. 2021. Nine months into 600 the COVID-19 pandemic: A longitudinal study showing mental health and movement 601 behaviours are impaired in UK students. International Journal of Environmental Research 602 and Public Health. 2021, 18, 2930. DOI 10.3390/ijerph18062930.

603 604 605 606

Savage MJ, James R, Magistro D, Donaldson J, Healy LC, Nevill M, Hennis PJ. 2020. Mental health and movement behaviour during the COVID-19 pandemic in UK university students: Prospective cohort study. Mental Health and Physical Activity, Volume 19, 2020, 100357.

607 DOI 10.1016/j.mhpa.2020.100357.

Sokolovsky AW, Hertel AW, Micalizzi L, White HR, Hayes KL, Jackson KM. 2021.

608 Preliminary impact of the COVID-19 pandemic on smoking and vaping in college students. Addictive Behaviors. 2021 Apr;115:106783. DOI 10.1016/j.addbeh.2020.106783.

Treisman R. 2020. How is each state responding to COVID-19? National Public Radio (npr). Available at https://www.npr.org/2020/03/12/815200313/what-governors-are-doing-totackle-spreading-coronavirus.

United States Census Bureau. 2021. QuickFacts, Lee County, Florida; Fort Myers city, Florida Available at https://www.census.gov/quickfacts/fact/table/leecountyflorida,fortmyerscityflorida/PST04521 9. Accessed July 1, 2021.

617 University System of Florida. 2020. Blueprint for Reopening Campuses. Available at 618 https://www.flbog.edu/the-state-university-system-of-florida-blueprint-for-reopening619 campuses-fall-semester-2020/. US college students during the COVID-19 pandemic: Cross-sectional survey study. Journal 622 of Medical Internet Research. 2020 Sep 17;22(9):e22817. DOI 10.2196/22817. 
623 Wathelet M, Duhem S, Vaiva G, Baubet T, Habran E, Veerapa E, Debien C, Molenda S, Horn 624 M, Grandgenèvre P, Notredame CE, D'Hondt F. 2020. Factors associated with mental health 625 disorders among university students in France confined during the COVID-19 pandemic. 626 JAMA Network Open. 2020;3(10):e2025591. DOI 10.1001/jamanetworkopen.2020.25591.

627 Wilson OWA, Holland KE, Elliott LD, Duffey M, Bopp M. 2021. The impact of the COVID-19 628 pandemic on US College Students' physical activity and mental health. Journal of Physical 629 Activity and Health. 2021 Feb 18;18(3):272-278. doi:10.1123/jpah.2020-032.

630 World Health Organization. 2020. Archived: WHO Timeline - COVID-19. Available at 631 https://www.who.int/news/item/27-04-2020-who-timeline---covid-19.

632 World Health Organization. 2021. Coronavirus disease (COVID-19) Timeline: WHO's COVID63319 response. Available at https://www.who.int/emergencies/diseases/novel-coronavirus634 2019/interactive-timeline\#! Accessed June 8, 2021.

635 Zandifar, A.; Badrfam, R. 2020. Iranian mental health during the COVID-19 epidemic. Asian 636 Journal of Psychiatry 2020;51:101990. DOI 10.1016/j.ajp.2020.101990.

637 Zhang Y, Zhang H, Ma X, Di Q. 2020. Mental health problems during the COVID-19 pandemic 638 and the mitigation effects of exercise: A longitudinal study of college students in China. 639 International Journal of Environmental Research and Public Health. 2020 May 640 25;17(10):3722. DOI 10.3390/ijerph17103722. 


\section{Table $\mathbf{1}$ (on next page)}

Independent variables included in the study and data analysis 


\begin{tabular}{|c|c|}
\hline Behaviors and Habits & Independent variable \\
\hline \multicolumn{2}{|l|}{ Sleeping habits } \\
\hline Hours of sleep per night & $\begin{array}{l}\text { Average number of hours slept per night (categorical data: } 4 \\
\text { hours or less; } 5 \text { hours; } 6 \text { hours; } 7 \text { hours; } 8 \text { hours; } 9 \text { hours; } 10 \\
\text { hours or more per night) }\end{array}$ \\
\hline Average time going to bed & $\begin{array}{l}\text { Average time of night going to bed (categorical data: before } \\
\text { 8pm; between } 8 \mathrm{pm} \text { and } 10 \mathrm{pm} \text {; between } 10 \mathrm{pm} \text { and } 12 \mathrm{am} \text {; after } \\
\text { 2am) }\end{array}$ \\
\hline \multicolumn{2}{|l|}{ Working } \\
\hline Do you work? & Categorical data (Yes; No) \\
\hline Average hours worked per week & $\begin{array}{l}\text { Average number of hours worked per week (categorical data: } \\
\text { [including all students who did not work]; under } 5 \text { hours; } 5-10 \\
\text { hours; } 10-20 \text { hours; } 20-30 \text { hours; } 30-40 \text { hours; over } 40 \text { hours) }\end{array}$ \\
\hline \multicolumn{2}{|l|}{ Physical activity } \\
\hline Physical activity & $\begin{array}{l}\text { Number of days per week with physical activity of at least } 60 \\
\text { minutes (continuous numerical data, range: } 0 \text { to } 7 \text { days) }\end{array}$ \\
\hline Strength training & $\begin{array}{l}\text { Number of days per week doing exercises to strengthen or } \\
\text { tone muscles (continuous numerical data, range: } 0 \text { to } 7 \text { days) }\end{array}$ \\
\hline \multicolumn{2}{|l|}{ Eating habits } \\
\hline Consumption of vegetables & $\begin{array}{l}\text { Number of times vegetables consumed in past } 7 \text { days } \\
\text { (categorical data: } 0 \text { times; } 1 \text { to } 3 \text { times; } 4 \text { to } 6 \text { times; } 7 \text { to } 10 \\
\text { times; } 11 \text { times or more) }\end{array}$ \\
\hline Consumption of fruit & $\begin{array}{l}\text { Number of times fruit consumed in past } 7 \text { days (categorical } \\
\text { data: } 0 \text { times; } 1 \text { to } 3 \text { times; } 4 \text { to } 6 \text { times; } 7 \text { to } 10 \text { times; } 11 \\
\text { times or more) }\end{array}$ \\
\hline Breakfast consumption & $\begin{array}{l}\text { Number of days breakfast eaten in past } 7 \text { days (continuous } \\
\text { numerical data, range: } 0 \text { to } 7 \text { days) }\end{array}$ \\
\hline Fast food consumption & $\begin{array}{l}\text { Number of times fast food consumed in past } 7 \text { days } \\
\text { (categorical data: } 0 \text { times; } 1 \text { to } 3 \text { times; } 4 \text { to } 6 \text { times; } 7 \text { to } 10 \\
\text { times; } 11 \text { times or more) }\end{array}$ \\
\hline Coffee consumption & $\begin{array}{l}\text { Number of cups of coffee consumed per day (categorical data: } \\
0 \text { cups, } 1-2 \text { cups, } 3-4 \text { cups, } 5-6 \text { cups, } 7 \text { cups or more) }\end{array}$ \\
\hline \multicolumn{2}{|l|}{ Online activity } \\
\hline $\begin{array}{l}\text { Time spent watching TV, movies, } \\
\text { reading news online }\end{array}$ & $\begin{array}{l}\text { Number of hours per day (categorical data: } 0 \text { hours, less than } 1 \\
\text { hour, } 1 \text { hour, } 2 \text { hours, } 3 \text { hours, } 4 \text { hours, } 5 \text { hours or more) }\end{array}$ \\
\hline $\begin{array}{l}\text { Time spent playing video or computer } \\
\text { games }\end{array}$ & $\begin{array}{l}\text { Number of hours per day (categorical data: } 0 \text { hours, less than } 1 \\
\text { hour, } 1 \text { hour, } 2 \text { hours, } 3 \text { hours, } 4 \text { hours, } 5 \text { hours or more) }\end{array}$ \\
\hline
\end{tabular}




\begin{tabular}{|c|c|}
\hline Vaping & $\begin{array}{l}\text { Number of days vaping in past } 7 \text { days (continuous numerical } \\
\text { data, range: } 0 \text { to } 7 \text { days) }\end{array}$ \\
\hline Alcohol consumption & $\begin{array}{l}\text { Number of days consuming at least one drink during the last } \\
30 \text { days (categorical data: } 0 \text { days, } 1-2 \text { days, 3-5 days, 6-9 days, } \\
10-19 \text { days, 20-29 days, all } 30 \text { days) }\end{array}$ \\
\hline Marijuana use & $\begin{array}{l}\text { Number of days using marijuana in past } 7 \text { days (continuous } \\
\text { numerical data, range: } 0 \text { to } 7 \text { days) }\end{array}$ \\
\hline \multicolumn{2}{|l|}{ Mental/emotional health } \\
\hline Difficulties concentrating 1 & Categorical data (Yes; No) \\
\hline Feeling sad or hopeless ${ }^{2}$ & Categorical data (Yes; No) \\
\hline Considered suicide ${ }^{3}$ & Categorical data (Yes; No) \\
\hline Number of time suicide considered ${ }^{4}$ & $\begin{array}{l}\text { Number of times over past } 12 \text { months (categorical data: } 1 \\
\text { time, 2-3 times, } 4-5 \text { times, } 6 \text { times or more) }\end{array}$ \\
\hline Planned suicide ${ }^{5}$ & Categorical data (Yes; No) \\
\hline Attempted suicide ${ }^{6}$ & Categorical data (Yes; No) \\
\hline
\end{tabular}

$2{ }^{1}$ Do you have serious difficulty concentrating, remembering, or making decisions because of a physical, 3 mental, or emotional problem?

$4 \quad{ }^{2}$ During the past 12 months, did you ever feel so sad or hopeless almost every day for two weeks or more 5 in a row that you stopped doing some usual activities?

$6 \quad{ }^{3}$ During the past 12 months, did you ever seriously consider attempting suicide?

$7 \quad{ }^{4}$ How many times did you consider attempting suicide?

$8 \quad{ }^{5}$ Did you make a plan about how you would attempt suicide?

$9 \quad{ }^{6}$ Did you actually attempt suicide? 


\section{Table 2 (on next page)}

Demographic characteristics of respondents for the pre-COVID (data collected between 04/2018 and 02/2020) and the COVID group (data collected between 11/2020 and 04/2021). 


\begin{tabular}{|l|c|c|}
\hline & $\begin{array}{c}\text { pre-COVID } \\
(04 / 2018-02 / 2020)\end{array}$ & $\begin{array}{c}\text { COVID } \\
(11 / 2020-04 / 2021)\end{array}$ \\
\hline Number of respondents & 721 & 506 \\
\hline Biological sex & & $83.8 \%$ \\
Female & $77.4 \%$ & $16.0 \%$ \\
Male & $21.4 \%$ & $0.2 \%$ \\
No information & $1.3 \%$ & $31.4 \%$ \\
\hline Age (mean \pm std. dev; range; median age) & $20.3 \pm 4.1 ; 18-61 ; 19$ & $20.6 \pm 4.8 ; 18-65 ; 19$ \\
\hline Student population & & $22.3 \%$ \\
Freshman & $32.2 \%$ & $12.7 \%$ \\
Sophomore & $27.2 \%$ & $1.8 \%$ \\
Junior & $24.4 \%$ & \\
Senior & $13.0 \%$ & $0.8 \%$ \\
Other (non-degree/second-degree & $2.4 \%$ & \\
seeking, graduate students) & & $32.2 \%$ \\
No information & $0.8 \%$ & $38.5 \%$ \\
\hline Living arrangements & & $20.0 \%$ \\
At home & $22.5 \%$ & $9.3 \%$ \\
On campus & $51.2 \%$ & \\
Off campus with others & $17.2 \%$ & \\
Off campus alone & $9.2 \%$ & \\
\hline
\end{tabular}

1 


\section{Table 3(on next page)}

Independent variables, number of respondents for each survey group, statistical test used, and adjusted p-values using the Benjamini-Hochberg procedure. 


\begin{tabular}{|c|c|c|c|c|}
\hline \multirow[t]{2}{*}{ Independent variable } & \multicolumn{2}{|c|}{ Number of respondents } & \multirow[t]{2}{*}{ Test } & \multirow[t]{2}{*}{ p-value } \\
\hline & $\begin{array}{c}\text { pre- } \\
\text { COVID }\end{array}$ & COVID & & \\
\hline Hours of sleep per night & 721 & 506 & $\begin{array}{l}\text { Pearson Chi-Square Test, Chi- } \\
\text { square }=29.890, \mathrm{DF}=6\end{array}$ & $0.0001 *$ \\
\hline Average time going to bed & 721 & 506 & $\begin{array}{l}\text { Pearson Chi-Square Test, Chi- } \\
\text { square }=22.942, \mathrm{DF}=4\end{array}$ & $0.0001 *$ \\
\hline Do you work? & 721 & 506 & $\begin{array}{l}\text { Pearson Chi-Square Test, Chi- } \\
\text { square }=3.452, \mathrm{DF}=1\end{array}$ & 0.0632 \\
\hline $\begin{array}{l}\text { Average hours worked per } \\
\text { week }\end{array}$ & 395 & 251 & $\begin{array}{l}\text { Pearson Chi-Square Test, Chi- } \\
\text { square }=5.510, \mathrm{DF}=5\end{array}$ & 0.3568 \\
\hline $\begin{array}{l}\text { Physical activity (aerobic } \\
\text { exercise) }\end{array}$ & 693 & 500 & $\begin{array}{l}\text { Kruskal-Wallis Rank Sums Test, } \\
\text { Chi-square }=9.3421, \mathrm{DF}=1\end{array}$ & $0.0022 *$ \\
\hline Strength training & 693 & 500 & $\begin{array}{l}\text { Kruskal-Wallis Rank Sums Test, } \\
\text { Chi-square }=2.2429, \mathrm{DF}=1\end{array}$ & 0.1342 \\
\hline Consumption of vegetables & 693 & 498 & $\begin{array}{l}\text { Pearson Chi-Square Test, Chi- } \\
\text { square }=1.591, \mathrm{DF}=4\end{array}$ & 0.8104 \\
\hline Consumption of fruit & 692 & 498 & $\begin{array}{l}\text { Pearson Chi-Square Test, Chi- } \\
\text { square }=2.726, D F=4\end{array}$ & 0.6046 \\
\hline Breakfast consumption & 692 & 499 & $\begin{array}{l}\text { Kruskal-Wallis Rank Sums Test, } \\
\text { Chi-square }=7.7713, \mathrm{DF}=1\end{array}$ & $0.0053 *$ \\
\hline Eating fast food Yes/No & 693 & 497 & $\begin{array}{l}\text { Pearson Chi-Square Test, Chi- } \\
\text { square }=4.513, \mathrm{DF}=1\end{array}$ & 0.0336 \\
\hline Fast food consumption & 693 & 497 & $\begin{array}{l}\text { Pearson Chi-Square Test, Chi- } \\
\text { square }=4.417, \mathrm{DF}=3\end{array}$ & 0.2198 \\
\hline Drinking coffee Yes/no & 690 & 500 & $\begin{array}{l}\text { Pearson Chi-Square Test, Chi- } \\
\text { square }=3.219, \mathrm{DF}=1\end{array}$ & 0.0728 \\
\hline Coffee consumption & 690 & 500 & $\begin{array}{l}\text { Pearson Chi-Square Test, Chi- } \\
\text { square }=5.229, \mathrm{DF}=3\end{array}$ & 0.1558 \\
\hline $\begin{array}{l}\text { Time spent watching } \mathrm{TV} \text {, } \\
\text { movies, reading news online }\end{array}$ & 721 & 505 & $\begin{array}{l}\text { Pearson Chi-Square Test, Chi- } \\
\text { square }=23.071, \mathrm{DF}=6\end{array}$ & 0.0008* \\
\hline $\begin{array}{l}\text { Time spent playing video or } \\
\text { computer games }\end{array}$ & 718 & 506 & $\begin{array}{l}\text { Pearson Chi-Square Test, Chi- } \\
\text { square }=36.963, \mathrm{DF}=6\end{array}$ & $0.0001 *$ \\
\hline Vaping & 236 & 185 & $\begin{array}{l}\text { Kruskal-Wallis Rank Sums Test, } \\
\text { Chi-square }=11.3200, D F=1\end{array}$ & $0.0008 *$ \\
\hline Drinking alcohol Yes/No & 523 & 499 & $\begin{array}{l}\text { Pearson Chi-Square Test, Chi- } \\
\text { square }=65.505, \mathrm{DF}=1\end{array}$ & $0.0001 *$ \\
\hline Alcohol consumption & 523 & 499 & $\begin{array}{l}\text { Pearson Chi-Square Test, Chi- } \\
\text { square }=6.649, \mathrm{DF}=4\end{array}$ & 0.1556 \\
\hline Marijuana use & 292 & 500 & Kruskal-Wallis Rank Sums Test, & $0.0001 *$ \\
\hline
\end{tabular}




\begin{tabular}{|l|c|c|l|c|}
\hline & & & Chi-square $=15.6320, \mathrm{DF}=1$ & \\
\hline Difficulties concentrating & 633 & 502 & $\begin{array}{l}\text { Pearson Chi-Square Test, Chi- } \\
\text { square }=77.283, \mathrm{DF}=1\end{array}$ & $\mathbf{0 . 0 0 0 1 *}$ \\
\hline Feeling sad or hopeless & 625 & 502 & $\begin{array}{l}\text { Pearson Chi-Square Test, Chi- } \\
\text { square = 5.686, DF =1 }\end{array}$ & $\mathbf{0 . 0 1 7 1 *}$ \\
\hline Considered suicide & 619 & 491 & $\begin{array}{l}\text { Pearson Chi-Square Test, Chi- } \\
\text { square }=0.259, \mathrm{DF}=1\end{array}$ & 0.6108 \\
\hline $\begin{array}{l}\text { Number of time suicide } \\
\text { considered }\end{array}$ & 78 & 59 & $\begin{array}{l}\text { Pearson Chi-Square Test, Chi- } \\
\text { square }=1.399, \text { DF }=3\end{array}$ & 0.7057 \\
\hline Planned suicide & 78 & 59 & $\begin{array}{l}\text { Pearson Chi-Square Test, Chi- } \\
\text { square }=2.762, \text { DF }=3\end{array}$ & 0.0965 \\
\hline Attempted suicide & 34 & 36 & $\begin{array}{l}\text { Pearson Chi-Square Test, Chi- } \\
\text { square }=0.229, \text { DF }=1\end{array}$ & 0.6324 \\
\hline
\end{tabular}

* denotes statistical significance

2 


\section{Table 4 (on next page)}

Questions exploring how COVID-related changes affected the emotional health of students with answer options. 


\begin{tabular}{|l|c|}
\hline \multicolumn{1}{|c|}{ Questions and answer options } & Responses \\
\hline Do you feel safe on campus this semester? & $\mathrm{n}=514$ \\
Yes & $24.7 \%$ \\
No & $75.3 \%$ \\
\hline \hline During the past 6 months have you felt yourself craving human interaction? & $\mathrm{n}=519$ \\
Yes & $76.7 \%$ \\
No & $23.3 \%$ \\
\hline \hline $\begin{array}{l}\text { Do you think the lack of social events this semester has affected your } \\
\text { mental/emotional health? }\end{array}$ & $\mathrm{n}=518$ \\
Yes & $54.4 \%$ \\
No & $45.6 \%$ \\
\hline \hline Has going to mostly virtual teaching affected your mental/emotional health? \\
Yes & $\mathrm{n}=517$ \\
No & $55.7 \%$ \\
\hline \hline $\begin{array}{l}\text { In comparison to previous semesters, do you find yourself more or less } \\
\text { connected to your peers?* }\end{array}$ & $44.3 \%$ \\
More & $\mathrm{n}=355$ \\
About the same & $\mathrm{n}=355$ \\
Less & $6.2 \%$ \\
\hline \hline $\begin{array}{l}\text { How motivated do you feel in your classes this semester compared with } \\
\text { previous semesters?* }\end{array}$ & $21.4 \%$ \\
Abore & $72.4 \%$ \\
\hline
\end{tabular}

1 *only students enrolled at FGCU during the previous semester were asked to respond 


\section{Table 5 (on next page)}

Ranking of emotions by percentage of respondents selecting up to ten words from a list of 39 words describing emotions $(n=504)$. 


\begin{tabular}{|c|l|c||c|l|c||c|l|c|}
\hline Rank & \multicolumn{1}{|c|}{ Emotion } & $\mathbf{\%}$ & Rank & Emotion & $\mathbf{\%}$ & Rank & Emotion & $\%$ \\
\hline 1 & Anxious & 70.0 & 14 & Gloomy & 21.4 & 27 & Confident & 14.0 \\
\hline 2 & Stressed & 64.6 & 15 & Optimistic & 20.6 & 28 & Miserable & 13.8 \\
\hline 3 & Overwhelmed & 58.8 & 16 & Neutral & 19.3 & 29 & Hopeless & 13.6 \\
\hline 4 & Disconnected & 58.4 & 17 & Sad & 18.3 & 30 & Engaged & 10.9 \\
\hline 5 & Tired & 54.9 & 18 & Indifferent & 18.1 & 31 & Demoralized & 9.9 \\
\hline 6 & Fatigued & 53.1 & 19 & Negative & 17.9 & 32 & Energized & 9.0 \\
\hline 7 & Alone & 47.9 & 20 & Unhappy & 16.5 & 33 & Relaxed & 8.6 \\
\hline 8 & Depressed & 38.9 & 21 & Distressed & 16.3 & 34 & Frightened & 8.2 \\
\hline 9 & Withdrawn & 33.9 & 22 & Angry & 16.1 & 35 & Peaceful & 8.2 \\
\hline 10 & Hopeful & 32.3 & 23 & Happy & 15.8 & 36 & Inspired & 7.0 \\
\hline 11 & Lonely & 30.4 & 24 & Positive & 15.8 & 37 & Upbeat & 3.5 \\
\hline 12 & Moody & 30.4 & 25 & Calm & 15.4 & 38 & Serene & 1.4 \\
\hline 13 & Empty & 25.9 & 26 & Powerless & 14.6 & 39 & Sanguine & 1.2 \\
\hline
\end{tabular}

